\title{
Biomarkers of exposure, antibodies, and respiratory symptoms in workers heating polyurethane glue
}

\author{
G Skarping, M Dalene, B-G Svensson ${ }^{\star}, M$ Littorin, B Åkesson, H Welinder, S Skerfving
}

\begin{abstract}
Objectives-The pathogenic basis of respiratory disorders associated with isocyanates are still obscure. One reason for this is the lack of good estimates of human exposure. In this study exposure was estimated by measurement of isocyanate metabolites in biological samples. Methods-In a factory using isocyanate based polyurethane (PUR) glue, isocyanate concentrations in air were measured by liquid chromatography. Samples from 174 employees were analysed for metabolites of 4,4'-methylene diphenyl diisocyanate (MDI) in plasma (P-MDX) and urine (U-MDX). After hydrolysis, 4,4'-methylenedianiline was measured by gas chromatography-mass spectrometry (GC-MS). The employees were screened for work related respiratory symptoms and tested for specific immunoglobulin $E$ (IgE) and IgG antibodies directed against isocyanate conjugated to human serum albumin.
\end{abstract}

Results-The time weighted isocyanate concentrations in air were low (MDI < 0.2-7; hexamethylene diisocyanate (HDI) $<0.1-0.7 ; 2,6$-toluene diisocyanate (TDI) $\left.<0.1 \mu \mathrm{g} / \mathrm{m}^{3}\right)$. All subjects had detectable $P-M D X$ and U-MDX. There were significant associations between the estimates of exposure to thermal degradation products of an MDI based glue and P-MDX (range $\leqslant 0 \cdot 10-5 \cdot 5 \mu \mathrm{g} / 1$ ), and U-MDX ( $\leqslant 0.04-5.0 \mu \mathrm{g} / \mathrm{g}$ creatinine); in cases of heavy exposure. P-MDX and $U$ MDX were associated with each other $(r=$ $0.64 ; P=0.0001)$, work related symptoms (P-MDX: $\quad P=0.03$; Mann-Whitney $U$ test), and serum concentrations of $M D I$ specific IgG antibodies $(r=0.26 ; P=$ 0.0007). Unexpectedly, high P-MDX and U-MDX concentrations were also encountered in workers cutting textile (PMDX 2.4-4.5 $\mu \mathrm{g} / 1$; U-MDX 0.81-3.8 $\mu \mathrm{g} / \mathrm{g}$ creatinine); the reason is still unknown. Equally unexpected, there were significant negative associations between $P$ MDX and liver function tests.

Conclusions-The results clearly show the value of biomarkers for isocyanate exposure; in particular, P-MDX is useful. Further, these results show the risk connected with thermal degradation of PUR.

(Occup Environ Med 1996;53:180-187)
Keywords: biomarkers; polyurethane glue

Isocyanates are used in the production of polyurethane (PUR) polymers, which are widely used in industry. Their main applications are as flexible and rigid foams, lacquers, and glues. 4,4'-Methylene diphenyl diisocyanate (MDI), hexamethylene diisocyanates (HDI), and 2,4- and 2,6-toluene diisocyanate (TDI) are the most frequently used isocyanates. Isocyanate exposure is associated with occupational hazards. ${ }^{1-4}$

The first step in the manufacturing of MDI is the reaction of aniline with formaldehyde. The main product is generally the $4,4^{\prime}$-methylene dianiline (MDA), but 2,2' - and 2,4'MDA are also formed. These products then react further with formaldehyde and aniline at free $o$ and $p$ positions, whereupon larger molecules are formed. Depending on the process several other components are formed. Isocyanates are then formed by the reaction of the amine group with phosgene. Thus, the technical product MDI is a mixture of a variety of isocyanates with different chemical structure.

The HDI and TDI have rather high vapour pressures, and exposure to the vaporous compounds may easily occur in an occupational setting. Conversely, the vapour pressure of MDI is low. However, an aerosol of MDI can result in exposure to $\mathrm{MDI}$. This is the case during spraying operations. Moreover, high exposure to isocyanates and amines occurs when PUR is thermally decomposed. ${ }^{5-8}$ Then more complex and new isocyanate compounds are formed. For example, at thermal decomposition of TDI based PUR, the 2-tolueneisocyanate-6-amine and 2,6-toluenediamine (TDA) have been detected. ${ }^{56}$ Exposure to isocyanates is often intermittent, with peaks, which occur both during production of PURs, and, in particular, at thermal decomposition. The complicated exposure pattern is one factor behind the lack of understanding of the pathomechanism behind isocyanate associated disease. Biological monitoring of exposure may add information.

Methods have been presented for the biological monitoring of exposure to $\mathrm{HDI}^{9}$ and $\mathrm{TDI}^{1011}$ by measurement of the corresponding amines in plasma or urine. Also, we have monitored the exposure in a worker performing thermal decomposition of an MDI based PUR, by measurement of MDA in hydrolysed
Accepted 29 September 1995

*Dr B-G Svensson died on 28 May 1995. 
urine. ${ }^{4}$ Recently, we encountered a worker with clear cut work related asthma, who was employed in a factory where workers handled isocyanate based glues. We decided to study the exposure, mainly to MDI and MDA, by the use of biological markers, in the workers of the factory, and to relate that to immunological sensitisation and symptoms. As MDA is hepatotoxic, ${ }^{12}$ we also screened the liver function.

\section{Materials and methods \\ FACTORY AND EXPOSURE}

The company was a subcontractor to the Swedish car industry manufacturing parts for the passenger room inside the car. The parts were made of textile, PUR, and special high performance fibre board. The work essentially took place in two large workshops with open doors in between.

Most of the workers were divided into small groups, three to six workers in each, manufacturing one single part or a few parts only. Inside the group the workers circulated between the different work operations. One of these work operations was spraying blue coloured glue of either MDI or HDI polymeric type on to the fibre board and the textiles.

During spraying the workers wore personal respiratory protection devices and rubber gloves. After the glue solvents had evaporated, the parts were heated to increase the reactivity of the glue, and then put together. The heating procedure was mainly performed by placing the parts under infrared heaters for 10-20 seconds and partly by air from heat guns. The temperature of the air ejected from these heat guns could be as high as $500^{\circ} \mathrm{C}$.

Other workers were permanently occupied with work tasks not involving MDI glue, for example cutting, sewing, electromagnetic welding, transport, repair work, assembling, and office work.

The technical grade MDI contains besides the 4,4'-MDI also 2,4-MDI, 2,2'-MDI, and polymeric isocyanates of various structures. ${ }^{13}$ Traces of phenyl isocyanate were also present. A small amount of an glue based on a PUR (HDI based) and an acrylcopolymer water dispersion was also used at the factory. The textile used was mainly coated with a layer of a TDI based flexible foam.

During this study the work usually took place in one shift. A few of the workers worked in two shifts.

\section{SUBJECTS}

The entire work force was 228 subjects. No former employees were included. In total, 174 employees were studied (mean age 42 , range 19-63). Of these 143 were women (mean age 42 , range 21-63), and 31 were men (mean age 41, range 19-59). Another nine subjects (five men) refused to participate. Out of the total work force 18 people were on long leave to take care of children at the time of the study, and $27(13 \%)$ people were on sick leave; those were not examined. Eighteen people (10 women) of those investigated did administrative work in an office, separated from the production rooms. They visited these rooms daily.

Mean duration of employment of the examined subjects was 9.4 (range 1-42) years, and $35 \%$ of the subjects were smokers. Atopy, defined as a history of hay fever, asthma, atopic eczema, or urticaria, was present in 29 subjects $(17 \%)$.

Twenty non-exposed subjects from another factory were used as controls for the antibody measurements.

\section{HEALTH EXAMINATIONS}

For each person a medical and an occupational history was obtained through a self administered questionnaire (modified from Nielsen et al). ${ }^{14}$ Questions were asked about allergic diseases (hay fever, asthma, atopic eczema, or urticaria) during childhood or adolescence, and smoking habits. Symptoms, both general, like fever and shivering, and local, from the eyes, nose, pharynx, or lower respiratory tract, were recorded. The completed questionnaires were scrutinised by a physician (BGS), who did a complementary interview. Asthma was defined as attacks of wheezing, dyspnoea, and cough. Work related symptoms were defined as those associated with work-that is, recovery during weekends or holidays. The physician was not aware of the exposure status of the employees.

Each subject gave a sample of venous blood; serum was analysed for $\gamma$-glutamyl transpeptidase, and aspartate and alanine aminotransferases, by routine clinical methods. The rest of the blood sample was used for the immunological investigations, and for analysis of MDX in blood plasma. Urine was collected from each subject at the end of a work shift.

Skin prick tests with conjugates between human serum albumin (HSA) and MDI, HDI, and TDI were performed on each subject.

MEASUREMENTS OF ISOCYANATES IN AIR

In workers handling isocyanate glue the exposure to monomeric isocyanates was measured in their personal breathing zone, during periods of 30-60 minutes by use of personal sampling pumps $(1 \mathrm{l} / \mathrm{min})$. The exposure was measured in nine work groups, six used MDI glue and three HDI glue. The isocyanate concentration in air was also measured in four different work areas in the two workshops.

Air samples were taken with SKC Model HFS 113 pumps (SKC, Eighty Four, USA) and $30 \mathrm{ml}$ midget impingers containing $10 \mathrm{ml}$ toluene with $1 \times 10^{-4} 9-(N$-methyl aminomethyl)-anthracene hydrochloride (MAMA) amine reagent. ${ }^{15}$ The analyses were performed by liquid chromatography (LC) with a UV detector $(1=254 \mathrm{~nm})$. The LC column was a $150 \times 3.2 \mathrm{~mm}$ Millipore Waters Bond Elut. The limits for measurement of a 60 minute sampling period were for $\mathrm{MDI}, \mathrm{HDI}$, and TDI $0 \cdot 2,0 \cdot 1$, and $0 \cdot 1 \mu \mathrm{g} / \mathrm{m}^{3}$ respectively. A Millipore Waters (Millipore-Waters, Milford, MA, USA) 600 multisolvent delivery system 
with a Waters 712 WISP with variable injection volume and a Waters 490 programmable multiwavelength detector. The mobile phase $(1 \mathrm{ml} / \mathrm{min})$ consisted of $80 \% / 20 \%$ acetonitrile/water with $1 \%$ triethylamine and $\mathrm{pH}$ adjusted to 3 with phosphoric acid.

\section{MEASUREMENT OF MDI METABOLITES IN PLASMA AND URINE Apparatus}

A VG Trio-1000 single quadrupole mass spectrometer (Fission Instruments, VG-Mass-Lab, Manchester, Cheshire, England) connected to a Carlo-Erba GC-8000 gas chromatograph equipped with an A200S autosampler (Fisons Instruments, Milan, Italy) was used. Chemical ionisation by ammonia with selected ion monitoring was used. Columns: fused silica columns with chemically bounded stationary phases, DB-5 (J and W Scientific, Folsom, CA, USA) $25 \mathrm{~m} \times 0.25 \mathrm{~mm}$ internal diameter with a film thickness of $0.25 \mu \mathrm{m}$ were used.

\section{Chemicals}

4,4-MDA (MDA) was from Fluka (Buchs, Switzerland), $\mathrm{HCl}, \mathrm{NaOH}$ and $\mathrm{K}_{2} \mathrm{HPO}_{4}$, from E Merck (Darmstadt, FRG); pentafluoroproprionic anhydride (PFPA), from Pierce (Rockford, IL, USA); acetonitrile and toluene, from Lab-Scan (Dublin, Ireland); and dideuterated 4,4'-MDA $\left(\mathrm{CD}_{2}\left[\mathrm{C}_{6} \mathrm{H}_{4} \mathrm{NH}_{2}\right]_{2}\right.$, MDDA) and MAMA from Synthelec (Lund, Sweden).

\section{Procedure}

Preparation of standard solutions: standard solutions of MDA were prepared by dissolving accurately weighted amounts in $0.1 \mathrm{M}$ hydrochloric acid. The solutions were further diluted to the appropriate concentrations.

Sampling, handling, and storing of biological samples: the urine samples were collected in polyethylene bottles. Density, creatinine (Department of Clinical Chemistry, University Hospital, Lund by use of KODAK EKTACHEM clinical chemistry slides (CREA) and a Kodak Ektachem 700 XR-C analyser), and pH (Neutralit, Merck; Darmstadt, Germany) were measured in each urine sample. The detection limit was about $0.04 \mu \mathrm{g} / \mathrm{l}$. The precision was about $6 \%$. Venous blood $(20 \mathrm{ml})$ was taken on each occasion. The urine and blood samples were stored in a freezer, at $-18^{\circ} \mathrm{C}$, until analysis. All analyses were done after acidic hydrolysis of the urine and plasma samples. The amounts given as $\mathrm{MDA}$ in figures therefore reflects the sum of free and hydrolysable compounds.

Samples $(n=174)$ for measurement of urinary MDA (U-MDA) and plasma MDA (PMDA) were obtained during a period of three weeks just before the summer vacation. The urine samples were taken immediately after the work shift and the plasma samples were taken during the day.

Work up procedure for biological samples: to a $1 \mathrm{ml}$ urine or plasma sample $100 \mu \mathrm{l}$ of a 1 $\mathrm{M} \mathrm{HCl}$ solution containing the internal standard MDDA $(6 \mathrm{ng} / \mathrm{ml})$ and $1.5 \mathrm{ml}$ of $3 \mathrm{M}$
$\mathrm{H}_{2} \mathrm{SO}_{4}$ were added. The sample was then hydrolysed at $100^{\circ} \mathrm{C}$ for 16 hours. A $5 \mathrm{ml}$ volume of saturated $\mathrm{NaOH}$ and $2 \mathrm{ml}$ of toluene were then added. The mixture was shaken for about 10 minutes and then centrifuged at $1500 \mathrm{~g}$ for five minutes. A $1.5 \mathrm{ml}$ volume of the organic layer was transferred to a new test tube and $20 \mu \mathrm{l}$ of PFPA was added. The mixture was immediately shaken vigorously for about 10 minutes. The excess of the reagent and acid formed were removed by extraction with $2 \mathrm{ml}$ of $1 \mathrm{M}$ phosphate buffer solution (pH 7.5). A $1 \mathrm{ml}$ volume of the toluene layer containing the amide derivative and the internal standard was transferred to a $1.5 \mathrm{ml}$ autosampler vial with a Teflon seal and was then ready to be injected into the gas chromatographymass spectrometry (GC-MS) system.

Measurements: GC-MS monitored the negative ions $\mathrm{m} / \mathrm{z}=470$ and $472,(\mathrm{~m} / \mathrm{z}=\mathrm{M}-20$, $\mathrm{M}=$ molecular weight) fragments of the MDA-PFPA and the $\left[{ }^{2} \mathrm{H}_{2}\right] \mathrm{MDA}-\mathrm{PFPA}$ derivative. Urine and plasma from the workers exposed to MDI were analysed. The samples were analysed on the GC-MS in batches of about 100 samples. Each batch of samples included two sets of calibration samples and each set of calibration samples included five concentrations of MDA in urine in the range of $0-4 \mu \mathrm{g} / \mathrm{l}$. The average correlation coefficient for eight GC-MS batches was 0.98 with the relative $\mathrm{SD}$ of $2 \%$. Area measurements were made, and for each plasma and urine sample two measurements, with duplicate injections, were made. The limit of detection was 0.05 $\mu \mathrm{g} / 1(0.3 \mathrm{nmol} / \mathrm{l})$ in plasma, about $0.1 \mu \mathrm{g} / \mathrm{g}$ creatinine $(0.06 \mu \mathrm{mol} / \mathrm{mol}$ creatinine $)$ in urine.

\section{IMMUNOLOGICAL EXAMINATIONS}

The antibodies were measured as previously described. ${ }^{1617}$

\section{Antigen preparations}

Conjugations of HDI and MDI HSA: HDI and MDI ( 32 and $21 \mathrm{~mol} / \mathrm{mol} \mathrm{HSA}$, respectively) were added to a solution of $\mathrm{HSA}$ in $0.05 \mathrm{M}$ boric acid $(0.05 \mathrm{M} \mathrm{KCl}, \mathrm{pH} 9.4)$. The conjugate preparations were purified from low molecular weight compounds $(<30000$ daltons) by filtration in an Amicon ultrafiltration cell (8200; Amicon, Danvers, MASS, USA). The proteins were lyophilised and reconstituted in $0 \cdot 1 \mathrm{M} \mathrm{NaHCO}_{3}$ when used.

Skin prick tests were performed with the hapten HSA conjugates already mentioned at an antigen concentration of $3.0 \mathrm{mg} / \mathrm{ml}$ in 0.1 $\mathrm{M} \mathrm{NaHCO}$. Reaction sizes were recorded in relation to histamine $(1 \mathrm{mg} / \mathrm{ml})$ response. ${ }^{18}$ Positive skin prick reaction was scored, when the size of the weal was at least half that induced by histamine.

\section{Radioallergosorbent test (RAST) of specific IgE antibodies}

The hapten HSA conjugates were bound to cyanogen bromide activated filter paper discs for use in the RAST. We used the Phadebas RAST system (Pharmacia Diagnostics AB, Uppsala, Sweden), according to the standard procedure. Results were expressed as percent- 
Table 1 Isocyanate concentrations in workers' breathing zones and in different work areas in a factory handling polyurethane glues

\begin{tabular}{|c|c|c|c|c|}
\hline \multirow[b]{2}{*}{ Work task } & \multirow{2}{*}{$\begin{array}{l}30-60 \text { Minutes } \\
\text { work groups } \\
n\end{array}$} & \multirow{2}{*}{$\begin{array}{l}\text { Sampling } \\
\text { periods } \\
n\end{array}$} & \multicolumn{2}{|c|}{ Isocyanate concentrations $\left(\mu g / m^{3}\right)$} \\
\hline & & & $\begin{array}{l}\text { MDI } \\
\text { median (range) }\end{array}$ & $\begin{array}{l}H D I \\
\text { median (range) }\end{array}$ \\
\hline \multicolumn{5}{|l|}{ Glueing:* } \\
\hline MDI glue & 6 & & $0.8 \dagger(<0.2-6)$ & $<0.1(<0.1-0.5 \ddagger)$ \\
\hline HDI glue & 3 & 12 & $<0.2(<0.2-3 \oint)$ & $0.2 \pi(<0.1-0.7)$ \\
\hline No glueing & 4 & 11 & $<0.2(<0.2-7 \cdot 1 \|)$ & $<0.1(<0.1-0.4 \S)$ \\
\hline
\end{tabular}

^Active glueing for more than half of the shift.

†Significantly different from the other work tasks $(P=0.01)$

$\ddagger$ One period $\geqslant 0.1 \mu \mathrm{g} / \mathrm{m}^{3}$.

Three periods $\geqslant 0.2 \mu \mathrm{g} / \mathrm{m}^{3}$

if Significantly different from the other work tasks $(P=0.0001)$.

TTwo periods $\geqslant 0 \cdot 2 \mu \mathrm{m}^{3}$.

$\|$ Two periods $\geqslant 0 \cdot 2 \mu \mathrm{g} / \mathrm{m}^{3}$
TDI was always $<0 \cdot 1 \mu / \mathrm{m}^{3}$.

Table 2 Concentrations of metabolites of $P-M D X$ and $U-M D X$ in workers exposed and clerks in a factory handling polyurethane glues

\begin{tabular}{|c|c|c|c|}
\hline Work task & $n$ & $\begin{array}{l}P-M D X(\mu \mathrm{g} / l) \\
\text { median (range) }\end{array}$ & $\begin{array}{l}U-M D X(\mu \mathrm{g} / g \text { creatinine) } \\
\text { median (range) }\end{array}$ \\
\hline \multicolumn{4}{|l|}{ Workers: } \\
\hline Cutting & 5 & $3 \cdot 7 \dagger(2 \cdot 4-4 \cdot 5)$ & $1 \cdot 1 \dagger(0 \cdot 81-3 \cdot 8)$ \\
\hline \multicolumn{4}{|l|}{ Glueing:^ } \\
\hline \multicolumn{4}{|l|}{ With heating: } \\
\hline MDI glue & 64 & $1 \cdot 8 \ddagger(\leqslant 0 \cdot 10-5 \cdot 5)$ & $0.37 \ddagger(\leqslant 0.04-5.0)(n=63)$ \\
\hline HDI glue & 4 & $0 \cdot 35(\leqslant 0 \cdot 10-1 \cdot 4)$ & $0.12(\leqslant 0.06-0.19)$ \\
\hline Without heating & 6 & $0 \cdot 77(\leqslant 0 \cdot 10-1 \cdot 1)$ & $0.14(\leqslant 0.05-0.33)(n=5)$ \\
\hline \multicolumn{4}{|l|}{ Other workers: } \\
\hline Repairmen & 6 & $1 \cdot 0(0 \cdot 43-2 \cdot 0)$ & $0.13(\leqslant 0.05-1.7)$ \\
\hline Other & 68 & $0 \cdot 76(\leqslant 0 \cdot 10-5 \cdot 2)$ & $\leqslant 0.09(\leqslant 0.04-2.7)$ \\
\hline Office & 21 & $\leqslant 0 \cdot 10 \$(\leqslant 0 \cdot 10-0.46)$ & $\leqslant 0.089(\leqslant 0.04-0.63)$ \\
\hline
\end{tabular}

*Active glueing for more than half of the work time.

†Significant differences from workers handling heated $\mathrm{MDI}$ glue $(n=64 ; \mathrm{P}-\mathrm{MDX}: \mathrm{P}=0.03$; U-MDX: $P=0 \cdot 02$ ).

Significant difference from workers, who did not cut $(n=84 ; \mathrm{P}-\mathrm{MDX}$ and U-MDX: $\mathrm{P}=$ 0.0001).

SSignificant difference from workers, who did not cut or handle heated MDI glue $(n=84$; P-MDX: $P=0.0001)$. No significant difference from workers who did not cut, or handle heated MDI glue $(n=84 ; U-M D X: P=0 \cdot 12)$.

age of specific binding (cpm of test disc-cpm of HSA disc) of total added radioactivity. Levels of specific binding $>0.3 \%$ were considered positive (highest control $0 \cdot 1 \%$ ).

Enzyme linked immunosorbent assay (ELISA) of specific IgG antibodies

Wells of polystyrene microtitre plates were coated by adding $100 \mu \mathrm{l}$ of the antigen solution $(150 \mu \mathrm{g} / \mathrm{ml} ; 0.005 \mathrm{~mol} / 1 \mathrm{PBS}, \mathrm{pH} 7 \cdot 2)$. The wells were washed and stored with blocking solution until use. Analytical procedure:

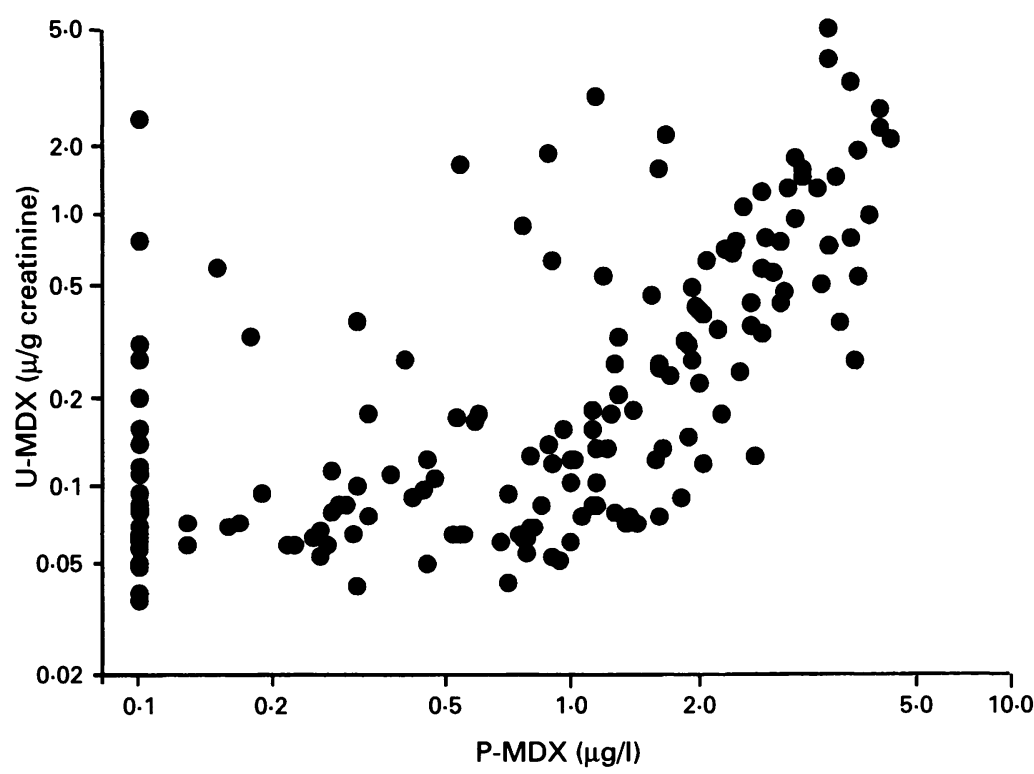

Figure 1 Concentrations of metabolites of $U-M D X$ and $P-M D X$ in workers and clerks in a factory handling polyurethane glue $(n=174 ; r=0.64 ; P=0.0001)$. The axes are logarithmic. (a) addition of a 1:50 dilution (phosphate buffered saline (PBS) merthiolate) of serum, (b) incubation, (c) addition of $100 \mu \mathrm{l}$ of an optimal dilution of alkaline phosphatase conjugated rabbit antihuman IgG, $(d)$ incubation at $20^{\circ} \mathrm{C},(e)$ addition of a substrate solution (disodium $p$-nitrophenol phosphate), and (f) incubation in darkness. Each serum sample was read (Titertek-Multiscan, Flow Laboratories, Eflab OY, Helsinki, Finland) at $405 \mathrm{~nm}$ (ELISA value). All samples were read against HSA antigen as a control of non-specific binding to the hapten HSA conjugate. Values higher than the highest values in the controls were regarded as positive.

\section{STATISTICAL METHODS}

Non-parametric statistics (Mann-Whitney $U$ test and Spearman's rank correlation coefficients $r$ ) were used for comparisons between groups, and for tests of correlations, respectively. Values were considered to be significant at $P \leqslant 0.05$. All tests were two tailed.

\section{Results}

The air concentrations of both MDI and HDI were low in all samples (table 1). As expected, tasks with MDI glue gave measurable low concentrations of MDI in air, and with $\mathrm{HDI}$ glue gave low measurable concentrations of $\mathrm{HDI}$ in air. Air concentrations of TDI were never detected-that is, they were well below $0 \cdot 1 \mu \mathrm{g} / \mathrm{m}^{3}$.

All subjects had detectable MDX concentrations in plasma and urine (table 2). Surprisingly, the highest median P-MDX was found in workers cutting fabric. Among the rest of the workers, those who heated MDI glue had higher concentrations than the others, who had, in turn, higher concentrations than the office clerks. Further, there was a decrease of P-MDX with rising age $(r=$ - 0.14; $P=0.05$ ). Moreover, the women had higher concentrations than the men (medians $1.1 v 0.4 \mu \mathrm{g} / 1 ; \mathrm{P}=0.0009$ ). There was no significant effect of smoking.

Again the cutters had the highest U-MDX values (table 2). Among workers who performed gluing, those who did not heat the glue had lower U-MDX values than those who heated the glue, among whom those using MDI glue had higher values than those handling HDI. Among subjects who did not glue, the repairers had values similar to the non-heating MDI gluers and HDI gluers, and the other workers and office clerks had lower values. Further, there was a decay of U-MDX with increasing age $(r=-0.18 ; P=0.01)$. Moreover, the women had higher values than the men (medians $21 v 7 \mu \mathrm{g} / \mathrm{g}$ creatinine; $\mathrm{P}=$ $0.0001)$. On the other hand, there was no significant difference between smokers and nonsmokers.

There was a weak, but significant association between U-MDX and P-MDX, although the U-MDX showed considerable variation at certain values of $\mathrm{P}-\mathrm{MDX}$, (fig 1 ).

The prevalence of work related symptoms was similar between workers with and without 
Table 3 Work tasks, work related symptoms, and specific serum antibodies against MDI or HDI in 174 workers and clerks in a factory handling polyurethane glue

\begin{tabular}{|c|c|c|c|c|c|c|c|c|}
\hline \multirow[b]{3}{*}{ Work task } & \multirow[b]{3}{*}{$n$} & \multirow{3}{*}{$\begin{array}{l}\text { Workers with } \\
\text { symptoms (n) }\end{array}$} & \multicolumn{2}{|c|}{ Symptoms from } & \multirow{2}{*}{\multicolumn{4}{|c|}{ Specific antibodies ( $n$ ) }} \\
\hline & & & Eyes or & Lower & & & & \\
\hline & & & nose or both & airways & $I g E-M D I$ & $I g G-M D I$ & $I g E-H D I$ & $I g G-H D I$ \\
\hline \multicolumn{9}{|l|}{ Workers: } \\
\hline Cutting & 5 & 1 & 1 & 1 & - & 2 & - & - \\
\hline \multirow{2}{*}{\multicolumn{9}{|c|}{$\begin{array}{l}\text { Glueing: } \\
\text { With heating: }\end{array}$}} \\
\hline & & & & & & & & \\
\hline MDI glue & 64 & 19 & 15 & 10 & 3 & 20 & - & 10 \\
\hline HDI glue & 4 & 2 & 1 & 1 & - & 1 & 1 & 1 \\
\hline Without heating & 6 & 2 & 1 & 2 & - & 2 & - & - \\
\hline \multicolumn{9}{|l|}{ Other workers: } \\
\hline Repairmen & 6 & 1 & 1 & - & - & - & - & - \\
\hline Other & 68 & 14 & 12 & 6 & - & 7 & - & 1 \\
\hline Office & 21 & - & - & - & - & 3 & - & 3 \\
\hline Total & 174 & 39 & 31 & 20 & 3 & 35 & 1 & 15 \\
\hline
\end{tabular}

IgE-MDI, IgE-HDI, IgG-MDI, and IgG-HDI = specific antibodies against MDI or HDI.

Table 4 Symptoms, specific serum antibodies against $M D A$ and metabolites of MDI in plasma $(P-M D X)$ and urine $(U-M D X)$ in workers and clerks $(n=174)$ in a factory handling polyurethane glue

\begin{tabular}{|c|c|c|c|}
\hline Symptoms and antibodies & $n$ & $\begin{array}{l}P-M D X(\mu \mathrm{g} / l) \\
\text { median (range) }\end{array}$ & $\begin{array}{l}U-M D X(\mu \mathrm{g} / g \text { creatinine) } \\
\text { median (range) }\end{array}$ \\
\hline \multicolumn{4}{|l|}{ Symptoms: } \\
\hline Absent & 113 & $0 \cdot 82^{\star}(\leqslant 0 \cdot 10-5 \cdot 5)$ & $0.13(\leqslant 0.04-3.8)$ \\
\hline \multicolumn{4}{|l|}{ Present: } \\
\hline Not work related & 22 & $0.74(\leqslant 0 \cdot 10-5 \cdot 2)$ & $0.16(\leqslant 0.06-2 \cdot 1)$ \\
\hline Work related & 39 & $1 \cdot 35^{\star}(\leqslant 0 \cdot 10-5 \cdot 2)$ & $0.19(\leqslant 0.04-5.0)$ \\
\hline \multirow{2}{*}{\multicolumn{4}{|c|}{$\begin{array}{l}\text { Antibodies: } \\
\text { IgE-MDI: }\end{array}$}} \\
\hline & & & \\
\hline Negative & 171 & $0.9(\leqslant 0.10-5.5)$ & $0.14(\leqslant 0.04-5.0)$ \\
\hline $\begin{array}{l}\text { Positive } \\
\text { IgG-MDI }\end{array}$ & 3 & $1.9(0.10,1.9,1.9)$ & $0.29(0.28,0.29,0.32)$ \\
\hline Negative & 136 & $0.9+(\leqslant 0.10-4.9)$ & $0.13 \ddagger(\leqslant 0.04-5.0)$ \\
\hline Positive & 35 & $1.9+(\leqslant 0 \cdot 10-5 \cdot 5)$ & $0.28 \mp(\leqslant 0.06-3.1)$ \\
\hline
\end{tabular}

$\star P=0.03 ;+P=0.005 ; \ddagger P=0.02$.

IgE-MDI and IgG-MDI = specific IgE and IgG antibodies, respectively, against MDI.

Table 5 Liver tests and metabolites of MDI in plasma (P-MDX), in workers and clerks $(n=168)$ in a factory handling polyurethane glue

\begin{tabular}{|c|c|c|c|c|}
\hline \multirow[b]{2}{*}{$P-M D X(\mu \mathrm{g} / l)$} & \multirow[b]{2}{*}{$n$} & \multicolumn{3}{|l|}{ Liver tests } \\
\hline & & $\begin{array}{l}S-G T(\mu k a t / l) * \\
\text { median (range) }\end{array}$ & $\begin{array}{l}S-A S A T(\mu k a t / l) \dagger \\
\text { median (range) }\end{array}$ & $\begin{array}{l}S-A L A T(\mu k a t / l) \ddagger \\
\text { median (range) }\end{array}$ \\
\hline $\begin{array}{l}<0.26 \\
0.26-0.91 \\
0.92-1.97 \\
>1.97\end{array}$ & $\begin{array}{l}42 \\
43 \\
40 \\
43\end{array}$ & $\begin{array}{l}0.20(0.10-0.90) \\
0.20(0.0-0.70) \\
0.20(0.0-0.40) \\
0.10(0.10-2.2)\end{array}$ & $\begin{array}{l}0.39(0.22-0.75) \\
0.36(0.25-0.69) \\
0.36(0.25-0.69) \\
0.32(0.20-0.68)\end{array}$ & $\begin{array}{l}0.32(0.04-0.93) \\
0.28(0.11-1.0) \\
0.20(0.11-0.87) \\
0.21(0.09-1.2)\end{array}$ \\
\hline
\end{tabular}

${ }^{\star} r=-0.20, \mathrm{P}=0.008 ; \dagger r=-0.27, \mathrm{P}=0.0006 ; \ddagger r=-0.28 ; \mathrm{P}=0.0002$.

$S$-GT $=\gamma$-glutamyl transpeptidase activity in serum; S-ASAT $=$ aspartate aminotransfertase; $S$-ALAT $=$ alanine aminotransferase. $r=$ Spearman's rank correlation coefficient. Reference limits: S-GT $<0.65 \mu \mathrm{kat} / 1$; S-ASAT $<0.7 \mu \mathrm{kat} /$; S-ALAT $<0.7 \mu \mathrm{kat} / 1$.

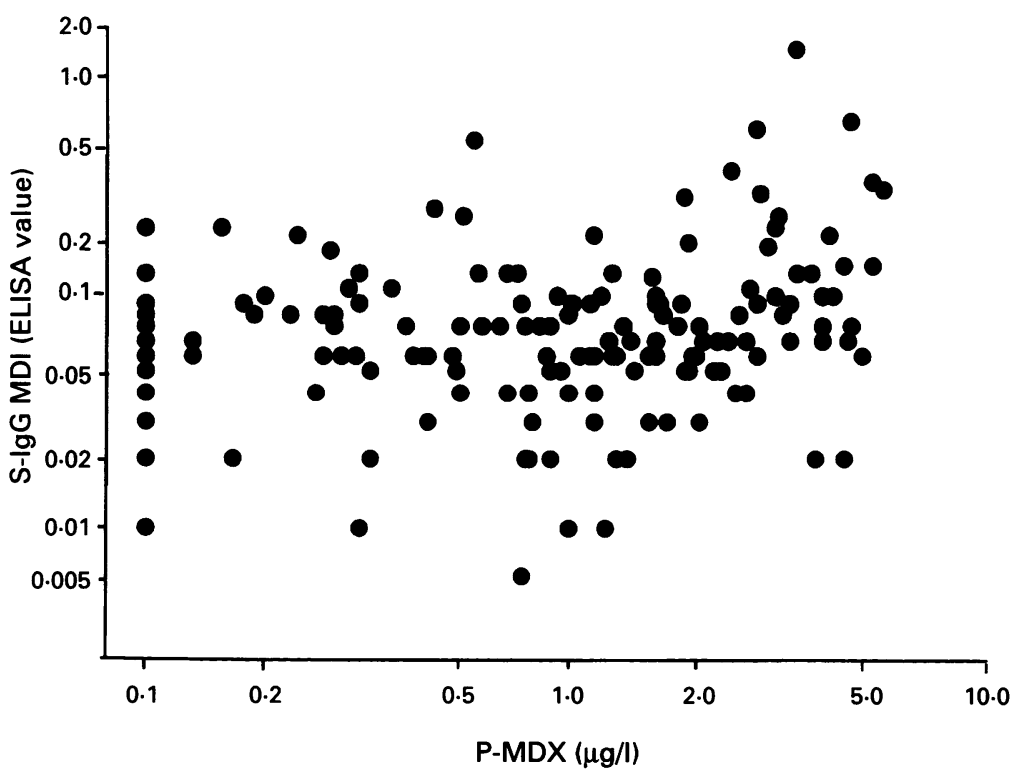

Figure 2 Concentrations of specific serum IgG antibodies to MDI (S-IgG-MDI) and $M D I$ metabolites in plasma (P-MDX), in workers exposed to MDI and clerks in a factory handling polyurethane glue $(n=174 ; r=0 \cdot 25, P=0 \cdot 0008)$. The axes are logarithmic. glueing in their works tasks (table 3). Thirty nine subjects experienced work related symptoms of the eyes, nose, lower airways, or a combination of these, at least once a week. Symptoms of the nose (blockage and secretion) dominated, and were present in 28 subjects. Only two subjects had work related asthma. Specific IgE antibodies against MDI were found in three subjects. Only one of these was symptomatic. One of the symptom free workers had IgE antibodies against HDI.

Specific IgG antibodies against MDI or HDI were more prevalent (table 3 ). However, only a few (11 out of 35 ) of the subjects with IgG antibodies to MDI had symptoms. Workers exposed to heated MDI glue had a higher prevalence of specific IgG antibodies against MDI than the others. Twelve of the workers with IgG antibodies to HDI also had IgG antibodies to MDI. One of the subjects with IgE antibodies to MDI also had IgG antibodies to MDI. Positive skin prick reaction against MDI conjugated to HSA was recorded for six subjects; three of those also reacted against HDI conjugated to HSA. None of the workers with a positive skin reaction was positive to RAST for specific IgE against HDI or MDI conjugated to HSA. The IgG antibody to MDI increased with rising age $(r=0.26 ; \mathrm{P}$ $=0.0007$ ). However, there were no associations with sex or smoking.

The workers with work related symptoms had higher concentrations of P-MDX than those without, or those with symptoms without clear association with work (table 4). There were no significant associations between work related symptoms and either sex, age, or smoking. Thus, there was no confounding by these factors.

Workers with IgG antibodies to MDI had significantly higher concentrations of P-MDX and U-MDX than workers without (table 4). Also, there were significant associations between IgG antibodies to MDI and P-MDX (fig 2) and U-MDX $(r=0.21 ; P=0.006)$. The three subjects with IgE antibodies to MDI had higher P-MDX and U-MDX than the others, but the group was too small to be sure of a significant association.

As the P-MDX and U-MDX concentrations were associated with both IgG antibodies to MDI and age, the possibility of confounding was considered by multiple regression 


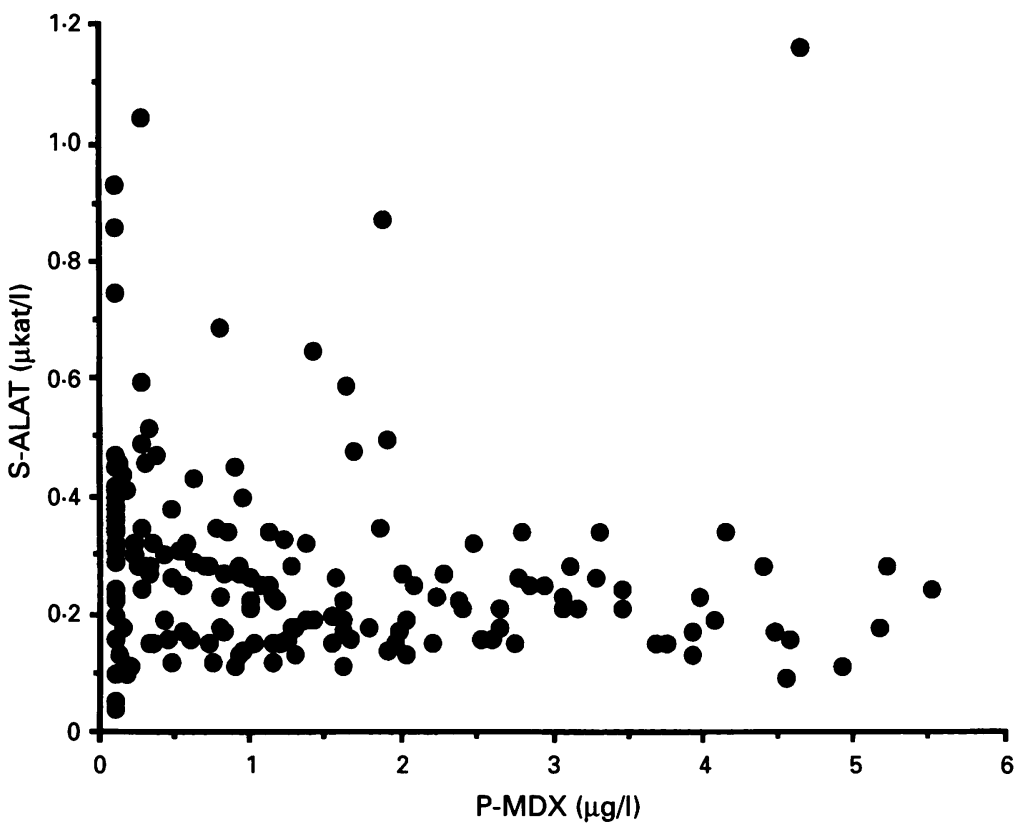

Figure 3 Liver test ( $S-A L A T=$ alanine aminotransferase activity in serum) and concentrations of metabolites of $M D I$ in plasma $P-M D X$, in workers and clerks in a factory handling polyurethane glue $(n=168 ; r=-0.28 ; P=0.0002)$.

analysis, after logarithmic transformations of the MDX and IgG variables. Then, there were still significant associations between IgG and both P-MDX $(P=0.0002)$ and U-MDX $(P=$ $0 \cdot 002)$. Hence, there were no indications of confounding from age.

Six subjects had liver enzyme activities above the reference concentrations (table 5). Only one of these subjects belonged to the quartile with the highest P-MDX concentrations. Surprisingly, there were significant negative associations between liver enzyme activities and P-MDX (for $\gamma$ glutamyl transpeptidase (GT) $r=-0.20$, $\mathrm{p}=0.008$; aspartate aminotransferase (ASAT) $r=-0.27, \mathrm{p}=0.0006$; alanine aminotransferase (ALAT) $r=-0.28, \mathrm{p}=0.0002$; fig 3), but not U-MDX.

\section{Discussion}

The main findings of this study were the higher concentrations of the MDI metabolites P-MDX and U-MDX in workers exposed to thermal degradation products of PUR based on MDI, and the higher prevalence of symptoms, likely to be caused by the isocyanate exposure, as well as specific IgG antibodies against MDI among those workers. This clearly shows the value of biomarkers for evaluation of isocyanate exposure and associated risks. Further, this study shows the risks connected with thermal degradation of PUR.

The handling of MDI based glue was, of course, associated with increased air concentrations of MDI, and HDI based glue with HDI. Concentrations of TDI were never detected. The present concentrations of monomeric isocyanates in air were low, far below the time weighted average (TWA) permissible exposure limits in Sweden for HDI (TWA during a working day was 30 , ceiling (for five minutes) was $70 \mu \mathrm{g} / \mathrm{m}^{3}$ ), MDI (50 and $100 \mu \mathrm{g} / \mathrm{m}^{3}$ ), and TDI (40 and $70 \mu \mathrm{g} / \mathrm{m}^{3}$ ). ${ }^{19}$

However, the present methods (as well as other chromatographic ones) do certainly not give a full picture of the exposure to isocyanates. Thus, the technical MDI contains several isocyanates other than the $4,4^{\prime}-\mathrm{MDI}$. Furthermore, these react with the polyol to give still others. Also, the spraying caused an exposure to aerosols of glues. Hence, there was an inhalation exposure to mainly aerosol MDI, which was not fully accounted for in the impinger sampling of air. Moreover, white smoke was observed when the workers were activating the glues containing isocyanate with the heat gun. The thermal decomposition of PUR is complex; a large variety of thermal degradation products are formed. However, there are no methods available for the complete analysis of these. Some low molecular weight isocyanate compounds are formed during the thermal decomposition of TDI and HDI based PUR. ${ }^{520}$ Then, not only the monomeric diisocyanates were found, but also compounds such as aminoisocyanates and amines, which in fact dominated. The toxicity of the aminoisocyanates is unknown. It is probable that MDI will decompose thermally in a similar way. The decomposition products formed are even more complex than in HDI and TDI due to the complex isomeric composition of technical grade MDI. No measurements of compounds in air can be made without reference compounds. Hence, in this study, only TDI, HDI, and 4,4'-MDI could be quantitatively measured. However, the presence of oligomeric compounds has been shown. ${ }^{21}$ This means that our estimates of the exposure may be considerably lower than all the isocyanates present. One important aspect of the thermal degradation is the high possibility of peak exposure, as heat was applied intermittently, and the degree of thermal degradation may differ over time, depending on the equipment and the skill of the worker. During the spraying operations, the workers were wearing personal respiratory protection devices: half mask with a charcoal filter for solvents, a prefilter for aerosols, and rubber gloves. There were, however, spraying periods, of unknown length and frequency, when the workers did not take advantage of the protection devices. Also, dermal exposure must be considered. Thus, the glue was blue in colour and it was easy to see droplets all over the gluing work sites, and after work most of the workers involved had numerous blue spots on the skin. The likelihood of considerable variation in air concentrations associated with thermal degradation over time and the intermittent use of personal protection devices, and the possibility of dermal uptake makes biological monitoring of exposure particularly relevant.

We measured the total $4,4^{\prime}-\mathrm{MDA}$ in plasma and urine after hydrolysis. The amount of free MDA in urine and plasma is negligible, as MDA is only seen after hydrolysis of the biological samples. In the TDI studies, we have shown that the half life of metabolites of TDA measured after hydrolysis, is about seven 
hours in urine, but as long as 20 days in plasma $^{22-24}$ (Skarping et al, personal communication). This indicates the presence of adducts to blood proteins. We do not know the chemical form of the MDI metabolites in urine. To stress that there was no amine in untreated plasma and urine (in fact, we do not know if amine was ever present in the body), we chose the metabolite MDX.

All subjects, even the clerks, who only occasionally entered the production area, had detectable P-MDX and U-MDX.

This is probably not due to exceptionally poor hygiene in the factory. At least, the working conditions are hardly different from similar work places manufacturing similar products. The ubiquitous presence of $\mathrm{MDX}$ is also our experience from other studies of subjects without occupational exposure (Skarping et al, personal communication). The measurement of $4,4^{\prime}-M D A$ is very specific. There is no known endogenous source of MDX. This indicates that all subjects are, to some extent, exposed to MDX precursors. Polyurethane is a very common polymer. Most of the PURs used are based on TDI and MDI. The reason for the background concentration of MDA in unexposed people is possibly the everyday exposure to degradation products of PUR polymers.

In accordance with these findings in subjects exposed to TDI, ${ }^{22-24}$ U-MDX most likely reflects recent $\mathrm{MDI}$ exposure (during the past few days), P-MDX the exposure for several weeks before sampling. This fact may also be the reason why the variation was larger for $\mathrm{P}$ MDX than for U-MDX and for air concentrations of isocyanates; there may have been occasional, very high exposure peaks, which may also be crucial for airways sensitisation, as proposed earlier. ${ }^{25}$ Thus, P-MDX may be a valuable tool to track the association between MDI exposure and respiratory disease.

Although most of the variation of P-MDX and U-MDX should be due to long and short term variations of the exposure, there might also be an effect of variation in metabolism between subjects, as found earlier for $\mathrm{TDI}^{22}$ and MDA. ${ }^{26}$

As expected, increased concentrations were found in workers handling MDI based glue, in particular in those heating the glue. However, subjects who cut fabric, unexpectedly, had the highest median P-MDX and U-MDX values. The reason for this is unknown. Some fabrics were laminated with TDI based PUR, but we are not aware of any association with MDI. Possibly the explanation is due to bystander exposure caused by thermal degradation in work operations a few metres away in combination with insufficient ventilation. This problem will be studied further.

The study is a cross sectional one, and a certain selection of healthy workers must be anticipated. Workers with symptoms may have left their employment. Also, the sick leave rate was high; six employees were on sick leave because of bronchial symptoms at the time of the study. Thus, the risk may have been underestimated. Further, several of the workers who experienced symptoms, had been moved to tasks with less exposure to glue. These had low MDX values. The symptoms were eyes and upper airway irritation, as well as lower airway irritation, including asthma, but not of hypersensitivity pneumonitis type. Of course, the present data do not allow firm conclusions on the medical nature of the complaints. It was not possible to perform lung function tests. However, spirometry and metacholine testing have later showed that many of the subjects with respiratory symptoms had lung function disturbances (Littorin et al personal communication). Symptoms were associated with P-MDX and U-MDX. The frequent symptoms, despite the low air concentrations of isocyanates found, may reflect sensitisation to isocyanates. However, there is a possibility of short peaks of isocyanates derived from thermal decomposition and not detected by available monitoring methods. The irritant effect of such is not known. Of course, we cannot be sure that the present symptoms were casually related to the isocyanate exposure. Thus, the thermal decomposition of PUR may give rise to a variety of other thermal decomposition products, for example, from the polyol ingredient. Some of these are irritants, for example, aldehydes. Also, the glueing workers were exposed to organic solvents such as acetone, ethyl acetate, methylethylketone, and toluene. However, the mean eight hour TWAs in their breathing zones were low: 32 (range 7-63), 12 (3-20), 11 (3-18), and $<1 \mathrm{mg} / \mathrm{m}^{3}$, respectively. Workers not handling glue were exposed to one tenth or less of these air concentrations.

The pathogenesis of respiratory disease associated with isocyanates has not been clarified and the role of specific antibodies is unclear. ${ }^{327} \mathrm{~A}$ low prevalence of specific $\mathrm{IgE}^{1}$ and IgG antibodies ${ }^{28} 25$ have been found in exposed workers. There may be an IgE-mediated mechanism in a subgroup of workers with diseases induced by isocyanate. Thus, Baur et al found a strong correlation between symptoms and positive findings of specific RAST and skin tests. ${ }^{29}$ However, Cartier et al, in specific provocation tests, found a better correlation with specific IgG than with IgE. ${ }^{30}$ Thus, the present findings are not surprising. Specific IgE was rarely encountered, neither in subjects with high exposure, nor in those with various symptoms. It is not known whether the lack of antibodies is because the complaints are not mediated through such a mechanism, or because other isocyanates in the technical grade or heated MDI PUR are responsible. There are at present no methods to measure antibodies to other components.

Interestingly, the findings for specific IgG antibodies were associated with P-MDX and U-MDX. Our results support the opinion that specific IgG is an index of exposure to isocyanates. ${ }^{1625}$ This is in accordance with the corresponding findings in workers exposed to organic acid anhydride. ${ }^{31}{ }^{32}$ However, the association between IgG and P-MDX was fairly weak. Further, the exposure may vary over time, and the kinetics of the MDI metabolites and the antibodies may be quite different. 
Our hypothesis was, at the start of the study, that any MDA exposure from the technical grade or heated MDI glue, possibly in combination with MDA formed during biotransformation of absorbed MDI, might affect the liver. However, unexpectedly, there were negative associations between several tests of liver function and P-MDX. (We are not aware of any earlier publications on this.) The reason for this is not known. It is probably not due to confounding. Possibly, it may be due to the enzyme inhibition; such as is caused by several isocyanates. $^{2}$

This work was supported by the Swedish Work Environment Fund and the Medical Faculty, Lund University. We thank Ms Anita Nilsson, RN, and Mr Mikael Adamsson for skilful technical assistance.

1 Hagmar L, Nielsen J, Skerfving S. Clinical features and epidemiology of occupational obstructive disease caused by small molecular weight organic chemicals. Monogr Allergy 1987;21:42-58.

2 Kennedy AL, Brown WE. Isocyanates and lung disease: experimental approaches to molecular mechanisms. Occupational medicine: state of the art review. Philadelphia: Hanley and Belfus, 1992;7:301

3 Vandenplas O, Malo J-L, Saetta M, Mapp CE, Fabbri LM. Occupational asthma and extrinsic alveolitis due to isocyanates: current status and perspectives. $\mathrm{Br} \mathcal{F}$ Ind $\mathrm{Med}$ 1993;50:213-28.

4 Littorin M, Truedsson L, Welinder H, Skarping G, Mårtensson U, Sjöholm AG. Acute respiratory disorder, rhinoconjunctivitis, and fever associated with pyrolysis of rhinoconjunctivitis, and fever associated with pyrolysis of
polyurethane derived from MDI. Scand $\mathcal{f}$ Work Environ polyurethane derived from
Health 1994;20:216-22.

5 Skarping G, Renman L, Sangö C, Mathiasson L, Dalene M. Capillary gas chromatographic method for the determination of complex mixture of isocyanates and amines. $f$ Chromatogr 1985;346:191-204.

6 Renman L, Sangö C, Skarping G. Determination of isocyanate and aromatic amine emissions from thermally degraded polyurethane's in foundries. Am Ind Hyg Assoc 7 1986;47:621-8.

7 Rosenberg C, Savolainen H. Mass fragmentographic determination of urinary amine metabolites in rats exposed to degradation products from heated rigid polyurethane. $f$ degradation products from heate
Chromatogr 1986;358:385-91.

8 Dalene M, Mathiasson L, Skarping G, Sangö C, Sandström JF. Trace analysis of airborne aromatic isocyanates and related aminoisocyanates and diamines using high-performance liquid chomatography with ultraviolet and electrochemical detection. $\mathcal{F}$ Chromatogr 1988;435:469-81.

9 Dalene M, Skarping G, Brorson T. Chromatographic determination of amines in biological fluids with special reference to the blogich amines. diamine (HDA) in humane urine using capillary gas chromatography and selective ion monitoring. $\mathcal{F}$ Chromatogr 1990;516:405-13.

10 Sandström J, Skarping G, Dalene $M$. Chromatographic determination of amines in biological fluids with special reference to the biological monitoring of isocyanates and amines. II. Determination of $2,4-$ and 2,6-toluenediamine (TDA) using glass capillary gas chromatography and selected ion monitoring (SIM). $\mathcal{F}$ Chromatogr 1989; 479:135-43.

11 Skarping G, Dalene $M$, Persson P. Biological monitoring of 2,4- and 2,6-toluenediisocyanate using capillary gas chromatography and selected ion monitoring. $f$ Chromatogr 1994;663:199-200.

12 Kopelman H, Robertsson MH, Sanders PG, Ash I. The Epping jaundice. $B M F$ 1966;1:514-6.

13 Skarping $G$, Dalene $M$. Determination of $4,4^{\prime}$-methylenedianiline (MDA) and identification of isomers in techni- cal-grade MDA in hydrolysed plasma and urine from workers exposed to methylene diphenyldiisocyanate by gas chromatography-mass spectrometry. $f$ Cromatogr 1995;663:209-16.

14 Nielsen J, Welinder H, Schütz A, Skerfving S. Specific serum antibodies against phthalic anhydride in occupationally exposed subjects. F Allergy Clin Immunol 1988; 82:126-33.

15 Sangö C, Zimerson E. A new reagent for determination of isocyanates in working atmospheres by HPLC using UV or fluorescence detection. fournal of Liquid Chromatography 1990;2:971-90.

16 Welinder H, Nielsen J, Bensryd I, Skerfving S. IgG antibodies polyisocyanates in car painters. Clin Allergy 1988; 18:85-93.

17 Welinder $\mathrm{H}$, Nielsen J. Immunologic tests of specific antibodies to organic acid anhydrides. Allergy 1991;46: $601-9$

18 Aas $\mathrm{K}$, Belin L. Standardization of diagnostic work in allergy. Int Arch Allergy 1973;45:57-60.

19 National Swedish Occupational Safety and Health Administration (Abetarskyddsstyrelsen). Occupational permissible exposure limits (Hygieniska gränsvärden). Stockholm: AFS 1993;9:86.

20 Skarping G, Dalene $M$, Mathiasson $M$. Trace analysis of airborne 1,6-hexamethylene diisocyanate and the related aminoisocyanate and diamine by glass capillary gas chromatography. $\mathcal{f}$ Chromatogr 1988;435:453-68.

21 Skarping G, Dalene M, Brunmark P. Liquid chromatography and mass spectrometry determination of aromatic phy and mass spectrometry determination of aromatic thermal degradation products of polyurethane. thermal degradation products

22 Brorson T, Skarping G, Sangö C. Biological monitoring of isocyanates and related amines. IV: 2,4- and 2,6-toluenediamine in hydrolysed plasma and urine after test-chamber exposure of humans to 2,4- and 2,6-toluenediisocyanate. Int Arch Occup Environ Health 1991;63:253-9.

23 Skarping G, Brorson T, Sangö C. Biological monitoring of isocyanates and related amines. III. Test chamber exposure of humans to toluene diisocyanate (TDI) Int Arch Occup Environ Health 1991;63:83-8.

24 Persson $P$, Dalene $M$, Skarping $G$, Adamsson $M$, Hagmar L. Determination of occupational exposure to toluenediisocyanate by biological monitoring in urine and plasma
by gas chromatography-mass spectrometry. $B r f$ Ind Med by gas chromatograt

25 Seldén AI, Belin L, Wass U. Isocyanate exposure and hypersensitivity pneumonitis- report of a probable case and prevalence of specific immunoglobulin $\mathrm{G}$ antibodies among exposed individuals. Scand $\mathcal{F}$ Work Environ Health 1989;15:234-344.

26 Brunmark P, Bruze M, Skerfving S, Skarping G. Biomonitoring of $4,4^{\prime}$-methylene dianiline by measurement in hydrolysed urine and plasma after epicutaneous exposure in humans. Int Arch Occup Environ Health 1995; sure in hur

27 Baur X, Marek W, Ammon J, Czuppon AB, Marcynski B, Raul-Heimsoth $M$, et al. Respiratory and other hazards of isocyanates. Int Arch Occup Environ Health 1994;66: 141-52.

28 Grammer LC, Eggum P, Silverstein M, Shaughnessy MA, Liotta JL, Patterson R. Prospective immunologic and clinical study of a population exposed to hexamethylene diisocyanate. F Allergy Clin Immunol 1988;82:627-33.

29 Baur X, Dewair M, Fruhmann G. detection of immunologically sensitised isocyanate workers by RAST and intracutaneous skin tests. $₹$ Allergy Clin Immunol 1984;73: cutane $610-8$.

30 Cartier A, Grammer L, Malo JL, Lagier F, Ghezzo $H_{\text {, }}$ Harris K, Patterson R. Specific serum antibodies against isocyanates: association with occupational asthma. $\mathcal{f}$ Allergy Clin Immunol 1989;84:507-14.

31 Welinder H, Nielsen J, Gustavsson C, Bensryd I, Skerfving S. Specific antibodies to methyltetrahydrophthalic anhydride in exposed workers. Clin Allergy 1990;20:639-45.

32 Welinder HE, Jönsson BAG, Nielsen J, Ottosson HE Gustavsson CA. Exposure-response relationships in the
formation of specific antibodies to hexahydrophthalic anhydride in exposed workers. Scand $\mathcal{f}$ Work Environ Health 1994;20:459-65.

33 Salvaggio JE. Recent advances in pathogenesis of allergic alveolitis. Clin Exp Allergy 1990;20:137-44. 